\title{
THE GEOCHEMICAL CARBON CYCLE AND THE UPTAKE OF FOSSIL FUEL $\mathrm{CO}_{2}$
}

\author{
James F. Kasting \\ Department of Geosciences, Penn State University, University Park, PA \\ 16802
}

James C. G. Walker

Space Physics Research Laboratory, University of Michigan, Ann Arbor, MI 48109

\begin{abstract}
Atmospheric carbon dioxide levels are controlled over long time scales by the transfer of carbon between the atmosphere, oceans, and sedimentary rocks -- a process referred to as the $\mathrm{CO}_{2}$ geochemical cycle. Carbon dioxide is injected into the atmosphere-ocean system by volcanism; it is removed by the weathering of silicate rocks on the continents followed by the deposition of carbonate minerals on the sea floor. Humans are currently perturbing the natural carbon cycle by burning fossil fuels and deforesting the tropics, both of which add $\mathrm{CO}_{2}$ to the atmosphere. The effects of human activities on future atmospheric $\mathrm{CO}_{2}$ levels can be estimated by including anthropogenic emissions in a model of the long-term carbon cycle. The model predicts that $\mathrm{CO}_{2}$ concentrations could increase by a factor of six or more during the next few centuries if we consume all of the available fossil fuels. Preserving existing forests and/or reforesting parts of the planet could mitigate the $\mathrm{CO}_{2}$ increase to some extent, but cannot be depended on to make a significant difference. Because the removal processes for atmospheric $\mathrm{CO}_{2}$ are slow, the maximum $\mathrm{CO}_{2}$ level reached is relatively insensitive to the fossil fuel burning rate unless the burning rate is many times smaller than its present value. The model also predicts that hundreds of thousands of years could pass before atmospheric $\mathrm{CO}_{2}$ returns to its original, preindustrial level. Implications of these results for future energy and land use policies are discussed.
\end{abstract}

\section{INTRODUCTION}

Most scientists and other informed citizens are aware that atmospheric carbon dioxide levels are currently increasing as a consequence of human activities. The increase has been carefully monitored since 1958 by a series of measurements performed at Mauna Loa, Hawaii ${ }^{1}$ (Fig. 1) and, more recently, at other locations around the globe. The Mauna Loa data show that atmospheric $\mathrm{CO}_{2}$ has increased more or less linearly from 315 parts per million (ppm) by volume in 1958 to about 


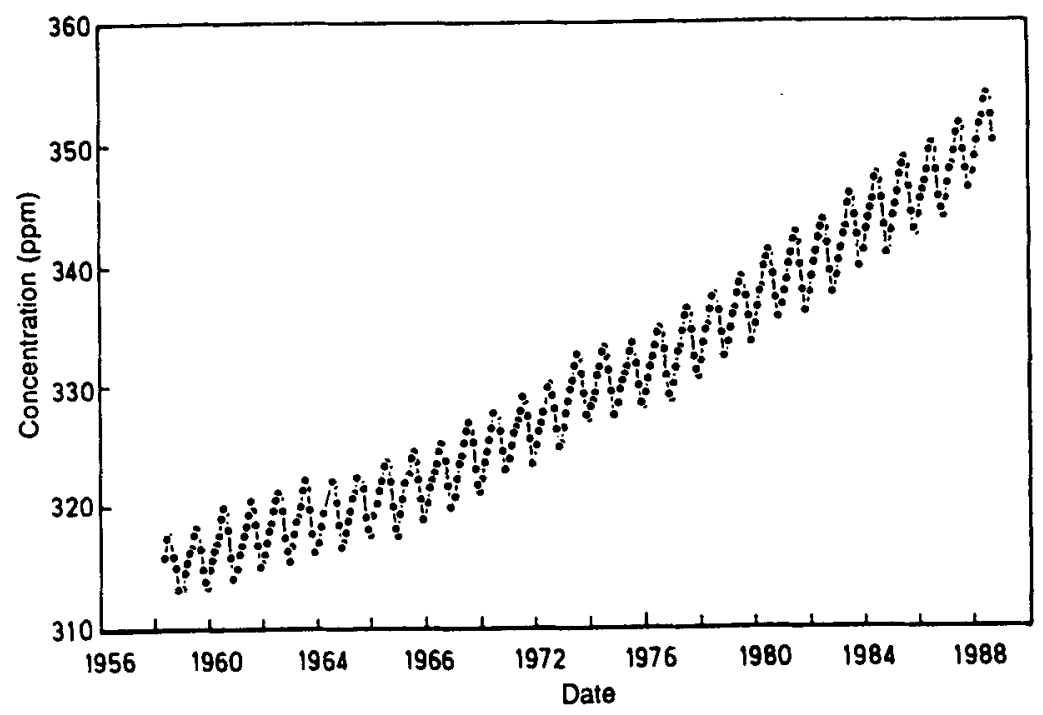

Fig. 1 Measurements of atmospheric $\mathrm{CO}_{2}$ made at Mauna Loa, Hawaii. This graph is often referred to as the 'Keeling curve,' because the measurements were begun by Charles Keeling. (From the Carbon Dioxide Information Analysis Center, Oak Ridge, Tennessee).

$350 \mathrm{ppm}$ today. Superimposed on this secular trend is a $5-6 \mathrm{ppm}$ seasonal cycle caused by terrestrial vegetation in the northern hemisphere. The seasonal cycle results from a relative excess of photosynthesis (which consumes $\mathrm{CO}_{2}$ ) in northern hemisphere summer, which is largely balanced by an excess of respiration (which produces $\mathrm{CO}_{2}$ ) during the winter. We shall not say too much about this biological carbon cycle here, since that is the subject of a separate chapter in this volume ${ }^{2}$. Some discussion of biology is unavoidable, however, as the increase in atmospheric $\mathrm{CO}_{2}$ levels over the past century, and perhaps over the next few centuries as well, is tied to both the geochemical and biological carbon cycles. In what follows, we shall try to illustrate the interrelationship between these cycles and to identify their relative importance for the fossil fuel $\mathrm{CO}_{2}$ problem.

Fewer people are aware that atmospheric $\mathrm{CO}_{2}$ levels have probably varied in the past for reasons that have nothing to do with human influence. The best documented case is the last glacial/interglacial cycle. Measurements of $\mathrm{CO}_{2}$ in air bubbles trapped in polar ice indicate that atmospheric $\mathrm{CO}_{2}$ increased from $\sim 200 \mathrm{ppm}$ at the peak of the last glaciation, 18,000 years ago, to $\sim 280 \mathrm{ppm}$ at the beginning of the current interglacial period, $\sim 10,000$ years $\mathrm{ago}^{3}$ (Fig. 2). The atmospheric $\mathrm{CO}_{2}$ concentration remained at roughly $280 \mathrm{ppm}$ until the middle of the last century, when 


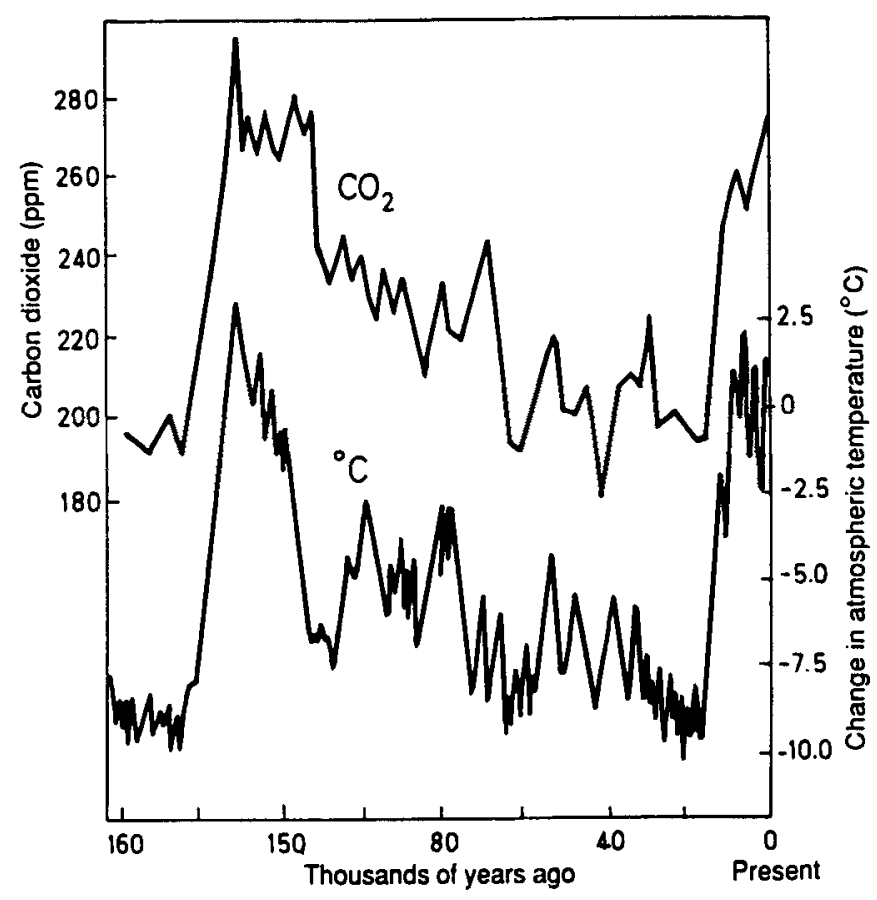

Fig. 2 Measurements of $\mathrm{CO}_{2}$ trapped in air bubbles in the core from Vostok, Antarctica. The temperature curve is inferred from measurements of the $\mathrm{D} / \mathrm{H}$ ratio of the ice. (From Barnola et al. ${ }^{3}$, as modified by Gribbin ${ }^{34}$.)

it began to rise towards its current higher level ${ }^{4.5}$. The cause of the glacial-tointerglacial $\mathrm{CO}_{2}$ variation is poorly understood. Most likely, it involves a change in the partitioning of dissolved carbon between the surface and deep ocean, possibly induced by a change in deep ocean circulation ${ }^{6.7}$ or by changes in the amount of calcium carbonate buried on continental shelves ${ }^{8}$.

On a somewhat longer time scale, there is reason to believe that atmospheric $\mathrm{CO}_{2}$ levels may have been significantly higher than today during the Cretaceous Period, which lasted from about 135 million years (m.y.) to 65 m.y. ago. Global surface temperatures appear to have been as much as $10^{\circ} \mathrm{C}$ warmer than at present based on the oxygen isotopic composition of carbonate sediments sampled by deep sea cores. (Oxygen has two important isotopes, ${ }^{16} \mathrm{O}$ and ${ }^{18} \mathrm{O} . \mathrm{CaCO}_{3}$ becomes enriched in ${ }^{18} \mathrm{O}$ compared to dissolved bicarbonate as seawater becomes colder. The ocean itself becomes enriched in ${ }^{18} \mathrm{O}$ in glacial periods because the ice in the polar caps is relatively enriched in ${ }^{16} \mathrm{O}$.) A likely cause for this warmth is increased 
atmospheric $\mathrm{CO}_{2}{ }^{10,11}$. On still longer time scales, greatly increased atmospheric $\mathrm{CO}_{2}$ levels (100 to 1000 times present) may have been required to compensate for reduced solar luminosity early in the Earth's history ${ }^{12,13}$. Direct evidence for these earlier fluctuations in atmospheric $\mathrm{CO}_{2}$ levels is lacking; however, there are good theoretical reasons why $\mathrm{CO}_{2}$ levels might have changed. The argument in each case hinges on the $\mathrm{CO}_{2}$ geochemical cycle, which controls atmospheric $\mathrm{CO}_{2}$ levels over long time scales. Since this same cycle is also involved in the uptake of fossil fuel $\mathrm{CO}_{2}$, it is worthwhile to consider how it works.

\section{THE $\mathrm{CO}_{2}$ GEOCHEMICAL CYCLE}

Carbon at the Earth's surface is stored in seven major reservoirs (Table 1). Of these, kerogen (dispersed, insoluble organic carbon in rocks) is probably the least important component from the standpoint of carbon cycling because it is relatively inert. (Much of the kerogen released by weathering is thought to be redeposited in sediments without undergoing oxidation.) Most of the fossil fuel reservoir consists of coal; oil and natural gas constitute less than 10 percent of the total ${ }^{14}$. The carbonate rock reservoir consists primarily of two different minerals: calcite $\left(\mathrm{CaCO}_{3}\right)$ and dolomite $\left(\mathrm{CaMg}\left(\mathrm{CO}_{3}\right)_{2}\right)$. The ocean contains three inorganic carbon species: carbonic acid $\left(\mathrm{H}_{2} \mathrm{CO}_{3}\right)$, bicarbonate ion $\left(\mathrm{HCO}_{3}{ }^{-}\right)$, and carbonate ion $\left(\mathrm{CO}_{3}{ }^{\circ}\right)$. (Chemical oceanographers prefer to denote carbonic acid as $\left(\mathrm{CO}_{2}\right)_{\mathrm{aq}}$; we use $\mathrm{H}_{2} \mathrm{CO}_{3}$ here to simplify the exposition.) Carbonic acid is produced when atmospheric $\mathrm{CO}_{2}$ dissolves in rainwater or seawater; bicarbonate and carbonate ion are produced when this (weak) acid dissociates

$$
\begin{aligned}
& \mathrm{CO}_{2}+\mathrm{H}_{2} \mathrm{O}-\mathrm{H}_{2} \mathrm{CO}_{3} \\
& \mathrm{H}_{2} \mathrm{CO}_{3} \rightarrow \mathrm{HCO}_{3}^{-}+\mathrm{H}^{+} \\
& \mathrm{HCO}_{3}^{-}-\mathrm{CO}_{3}^{-}+\mathrm{H}^{+}
\end{aligned}
$$

The equilibrium constants for these reactions are well known and are tabulated in 
Broecker and Peng ${ }^{14}$ (p. 151).

The $\mathrm{CO}_{2}$ geochemical cycle describes how the various inorganic carbon species move from one reservoir to another. Which transfer processes are most important depends on the time scale of interest. The time required to effectively transfer $\mathrm{CO}_{2}$ between the atmosphere and the ocean is of the order of the deep ocean mixing time, $\sim 1000$ years. Over periods much longer than this, it is convenient to consider the atmosphere and ocean as a single combined reservoir. The $\mathrm{CO}_{2}$ content of this reservoir is determined by the balance between the weathering of silicate minerals on the continents and the release of $\mathrm{CO}_{2}$ by volcanism. If one represents all silicates by the mineral wollastonite, $\mathrm{CaSiO}_{3}$, the process of silicate weathering can be written as

$$
\mathrm{CaSiO}_{3}+2 \mathrm{CO}_{2}+\mathrm{H}_{2} \mathrm{O} \rightarrow \mathrm{Ca}^{++}+2 \mathrm{HCO}_{3}^{-}+\mathrm{SiO}_{2}
$$

The calcium and bicarbonate ions released by weathering are carried by streams and rivers to the oceans. There, organisms use them to make shells of calcium carbonate

$$
\mathrm{Ca}^{++}+2 \mathrm{HCO}_{3}^{-}-\mathrm{CaCO}_{3}+\mathrm{CO}_{2}+\mathrm{H}_{2} \mathrm{O}
$$

When these organisms die, their shells fall toward the ocean floor. Many of them redissolve on the way down, but some (primarily those that fall in shallower regions) survive and are buried in sediments. The net effect of these two processes can be determined by adding reactions (4) and (5) to get

$$
\mathrm{CaSiO}_{3}+\mathrm{CO}_{2} \rightarrow \mathrm{CaCO}_{3}+\mathrm{SiO}_{2}
$$

The combination of these two processes removes $\mathrm{CO}_{2}$ from the atmosphere-ocean system and sequesters it in carbonate sediments. The $\mathrm{SiO}_{2}$ in reaction (6) is used by diatoms to make shells of opal; this opal is later transformed into the common mineral quartz.

If this were all that were happening, the story of Earth's climate evolution would be short and unhappy. The current rate of calcium carbonate deposition is sufficient to exhaust the carbon in the atmosphere-ocean system in about 400,000 years. Without $\mathrm{CO}_{2}$, the atmosphere would become extremely cold, the oceans would freeze, and the Earth would become uninhabitable. Evidently, some process must return carbon to the system so that this does not happen. The return process is called carbonate metamorphism or, equivalently, silicate reconstitution. It works in the following manner: The sea floor is continually spreading outward from the midocean ridges as part of the process of plate tectonics. In some areas, old, carbonate-laden sea floor is subducted down into the mantle. When this occurs, the carbonate sediments are heated and metamorphosed; calcium carbonate reacts with quartz to reform calcium silicate, i.e. reaction (6) is reversed, and gaseous $\mathrm{CO}_{2}$ is released. Some of this $\mathrm{CO}_{2}$ makes its way back to the Earth's surface and is vented into the atmosphere through volcanos and hot springs. The total carbon content of the atmosphere-ocean system remains constant provided that the rate of $\mathrm{CO}_{2}$ outgassing is equal to the rate of consumption of $\mathrm{CO}_{2}$ by silicate weathering followed by 
carbonate deposition.

Observationally, one can estimate the weathering rate by measuring the concentrations of dissolved calcium, bicarbonate, and silica in river water and multiplying by the total discharge rate of the world's rivers. The measured values correspond to $\mathrm{CO}_{2}$ consumption rates of about (6-7) $\times 10^{12}$ moles yr ${ }^{-1}{ }^{10,17}$. The $\mathrm{CO}_{2}$ outgassing rate is difficult to measure directly; recent attempts to do so ${ }^{18,19}$ indicate that it is within a factor of two of the $\mathrm{CO}_{2}$ consumption rate. The usual assumption made by modelers (including us) is that these two rates are equal, so that the system is in steady state on long time scales.

With these thoughts in mind, let us return briefly to the two, long-term, paleoclimate problems mentioned in the previous section. Could the geochemical carbon cycle explain the warmth of the Cretaceous? Berner and coworkers ${ }^{10}$ have argued that it could. Seafloor spreading rates appear to have been faster at that time, as evidenced by the positions of magnetic lineations on the ocean floor. Faster seafloor spreading should lead to faster rates of carbonate metamorphism and increased volcanic outgassing of $\mathrm{CO}_{2}$. It should also have caused sea level to increase, in agreement with evidence from the geologic record. Higher sea level implies less continental area exposed to weathering and, hence, a reduced loss rate for atmospheric $\mathrm{CO}_{2}$. The combination of high $\mathrm{CO}_{2}$ production and low $\mathrm{CO}_{2}$ loss could have produced atmospheric $\mathrm{CO}_{2}$ concentrations several times higher than the present value. This, in turn, might account for the observed climatic warmth.

What about the faint young sun problem? Could the geochemical carbon cycle have prevented the oceans from freezing early in Earth's history? Walker and coworkers $^{20}$ have shown that it might have. Consider the extreme case first: If the oceans had frozen completely, silicate weathering would have virtually ceased and volcanic $\mathrm{CO}_{2}$ would have simply accumulated in the atmosphere. Eventually, the greenhouse effect produced by this $\mathrm{CO}_{2}$ would have become large enough to melt the ice. (Recall from Table 1 that the amount of $\mathrm{CO}_{2}$ tied up in carbonate rocks is very large.) In a more realistic model, global glaciation would probably never occur, atmospheric $\mathrm{CO}_{2}$ concentrations would increase in such a way as to ensure the continued presence of liquid water. Indeed, increased volcanism and reduced continental area in the Earth's early history could have resulted in extremely high atmospheric $\mathrm{CO}_{2}$ levels and a climate that was warmer than today, despite the weaker solar input ${ }^{21,22}$.

To sum up: The general outlines, if not the details, of the geochemical carbon cycle are reasonably well understood. The operation of this cycle over long time scales can explain patterns in Earth's paleoclimatic history that might otherwise be difficult to understand. In the remaining parts of this chapter, we will show that the geochemical carbon cycle is also relevant to the present problem of global warming caused by the release of fossil fuel and biospheric $\mathrm{CO}_{2}$.

\section{MODERN $\mathrm{CO}_{2}$ SOURCES AND SINKS}

The rise in $\mathrm{CO}_{2}$ concentrations illustrated in Figure 1 is a consequence of human perturbations to the natural carbon cycle. The primary anthropogenic $\mathrm{CO}_{2}$ 
sources are the burning of fossil fuels and tropical deforestation (Table 2). The rate of fossil fuel consumption is well known; the rate of deforestation is highly uncertain. The highest estimates of the deforestation rate place it on a par with the burning of coal and oil, but the actual rate could be lower by a factor of as much as seven. The number to which both of these anthropogenic $\mathrm{CO}_{2}$ sources should be compared is the $\mathrm{CO}_{2}$ outgassing rate from volcanos; this represents the net input rate of $\mathrm{CO}_{2}$ to the atmosphere-ocean system prior to human influence. That rate is 50 to 100 times smaller than the current rate of fossil fuel usage. This is the first, and possibly the most important, lesson to be learned from considering the current global warming problem in the context of the long-term geochemical carbon cycle. To reduce the rate of atmospheric $\mathrm{CO}_{2}$ increase to near zero would require roughly a hundred-fold reduction in the rate of fossil fuel consumption, all other things being equal. This constraint is much more severe than other estimates that have appeared in both the scientific and popular literature. It has obvious implications for future energy policy, to which we will return at the end.

The $\mathrm{CO}_{2}$ added to the atmosphere by fossil fuel burning and deforestation will be removed by a variety of processes. We have already discussed the ultimate sink for this $\mathrm{CO}_{2}$ : silicate weathering followed by carbonate deposition (reactions 4-6 above). The previous discussion, however, treated the atmosphere and ocean as a single reservoir and neglected the biological carbon cycle entirely. Since we are concerned at present with both the long- and short-term response of the system to human activities, it is necessary to consider as well the processes that transfer $\mathrm{CO}_{2}$ from the atmosphere to the ocean and to the terrestrial biosphere.

One process that can potentially remove $\mathrm{CO}_{2}$ from the atmosphere is photosynthesis which, from a physicist's point of view, can be written as

$$
\mathrm{CO}_{2}+\mathrm{H}_{2} \mathrm{O} \rightarrow \mathrm{CH}_{2} \mathrm{O}+\mathrm{O}_{2}
$$

Here, ' $\mathrm{CH}_{2} \mathrm{O}$ ' is shorthand for more complex forms of organic matter. Photosynthesis removes approximately $1 / 10$ of all the atmosphere's $\mathrm{CO}_{2}$ every year ${ }^{17}$; however, most of this is returned almost immediately by respiration, which is just the reverse of reaction (7). A growing tree photosynthesizes slightly more than it respires, resulting 
in a net uptake of $\mathrm{CO}_{2}$. This $\mathrm{CO}_{2}$ is returned to the atmosphere when the tree dies and decays. Thus, a steady-state forest is neither a source nor a sink for $\mathrm{CO}_{2}$. In order for photosynthesis to act as a net $\mathrm{CO}_{2}$ sink, it is necessary to upset this steady state. If the amount of forested land increases, or if the trees in extant forests grow larger, or if soil carbon storage increases, $\mathrm{CO}_{2}$ can be effectively sequestered into the biospheric and soil carbon reservoirs. Table 1 shows that these two reservoirs currently contain about $1 / 2$ to $1 / 3$ times as much carbon as is stored in fossil fuels. Thus, if one were able to double the size of these reservoirs through extensive reforestation, one could conceivably soak up half of the $\mathrm{CO}_{2}$ that may eventually be released from the burning of fossil fuels. If, on the other hand, the present deforestation trend continues, the transfer of carbon will be in the opposite direction and the biosphere will act as a net source for atmospheric $\mathrm{CO}_{2}$. Obviously, current land use practices will have to change dramatically if photosynthesis is to become a net $\mathrm{CO}_{2}$ sink.

Another way that fossil fuel $\mathrm{CO}_{2}$ can be removed is by dissolution in the oceans. Reactions (1)-(3) above show what happens chemically when $\mathrm{CO}_{2}$ dissolves in water. But there is an added complication when one considers the atmosphereocean system: the ocean already contains a large amount of dissolved inorganic carbon (60 times the amount in the atmosphere) in the form of bicarbonate and carbonate ions (Table 1). If the extra fossil-fuel-generated $\mathrm{CO}_{2}$ simply dissolved according to reactions (1)-(3), the ocean would rapidly become more acidic, i.e. its $\mathrm{pH}$ would decrease. This would shift the equilibria in reactions (2) and (3) to the left, resulting in a conversion of dissolved bicarbonate and carbonate ion into carbonic acid. Since atmospheric $\mathrm{CO}_{2}$ is in approximate equilibrium with the carbonic acid in surface water, this feedback would make it difficult for the ocean to absorb much additional $\mathrm{CO}_{2}$. What actually happens, therefore, is somewhat more complicated. Most of the anthropogenic $\mathrm{CO}_{2}$ that dissolves in the ocean reacts with carbonate ions to yield bicarbonate

$$
\mathrm{CO}_{2}+\mathrm{CO}_{3}^{*}+\mathrm{H}_{2} \mathrm{O}-2 \mathrm{HCO}_{3}^{-}
$$

This reaction buffers the ocean's $\mathrm{pH}$ and allows it to absorb substantial quantities of anthropogenic $\mathrm{CO}_{2}$. The amount that can be taken up in this manner is approximately equal to the total amount of carbonate ion in the oceans, about $12 \times 10^{16}$ moles $^{14}$. This is roughly $1 / 3$ to $1 / 4$ of the amount of carbon available in fossil fuels.

Additional $\mathrm{CO}_{2}$ can be transferred from the atmosphere to the ocean by taking advantage of the buffering capacity of carbonate sediments and rocks. $\mathrm{CO}_{2}$-rich water can dissolve calcium carbonate according to the reaction

$$
\mathrm{CO}_{2}+\mathrm{CaCO}_{3}+\mathrm{H}_{2} \mathrm{O}-\mathrm{Ca}^{++}+2 \mathrm{HCO}_{3}^{-}
$$

This reaction is similar to reaction (8), except for the addition of calcium to the reactants and to the products. The calcium carbonate that participates in reaction (9) can come from either seafloor sediments or from exposed carbonate rocks on the continents. (Dolomite, $\mathrm{CaMg}\left(\mathrm{CO}_{3}\right)_{2}$, can be dissolved by a reaction similar to reaction 
Table 3. Sinks for $\mathrm{CO}_{2}$

\begin{tabular}{|c|c|c|}
\hline Sink & $\begin{array}{l}\text { Uptake capacity } \\
\left(10^{16} \text { moles } \mathrm{CO}_{2}\right)\end{array}$ & $\begin{array}{l}\text { Timescale } \\
\text { (Yrs) }\end{array}$ \\
\hline Photosynthesis & -18 to $+18^{a}$ & $50-100$ \\
\hline $\begin{array}{l}\text { Dissolution in the } \\
\text { ocean }\end{array}$ & $12^{b}$ & $-10^{3}$ \\
\hline $\begin{array}{l}\text { Dissolution of carbonate } \\
\text { sediments }\end{array}$ & $40^{\mathrm{b}}$ & $10^{3}-10^{4}$ \\
\hline $\begin{array}{l}\text { Carbonate weathering on } \\
\text { land }\end{array}$ & $5 \times 10^{5 c}$ & $10^{4}-10^{5}$ \\
\hline $\begin{array}{l}\text { Silicate weathering on } \\
\text { land }\end{array}$ & $\sim 10^{6} \mathrm{c}$ & $10^{5}-10^{6}$ \\
\hline $\begin{array}{l}{ }^{a} \text { See text } \\
{ }^{b} \text { Ref. } 14 \\
{ }^{c} \text { Ref. } 10\end{array}$ & & \\
\hline
\end{tabular}

(9)). It is generally thought that dissolution of seafloor carbonate sediments will provide the greatest amount of $\mathrm{CO}_{2}$ buffering over the next few centuries. The amount of carbonate that might eventually be exposed to corrosive seawater is difficult to estimate because it depends on such factors as the depth to which worms burrow into the sediments. Broecker and Peng ${ }^{14}$ place the figure at about $40 \times 10^{16}$ moles. This is enough buffering capacity to neutralize most or all of the carbon in fossil fuels, were it all to be effectively utilized. Even more buffering capacity is available from carbonate rocks stored on the continents, but utilization of that capacity is expected to be slower because it relies on the slow process of rock weathering. Some models nevertheless predict that this could be an important factor on the 1,000 to 10,000 -year time scale (see next section).

It is instructive, at this point, to say a few more words about time scales. The time scale for anthropogenic $\mathrm{CO}_{2}$ release can be estimated by dividing the fossil fuel inventory (Table 1 ) by the current consumption rate (Table 2 ). This gives a release time of 700 to 1000 years, depending on the estimated size of the recoverable fossil fuel reservoir. This release time is admittedly uncertain because it assumes that the 
present rate of burning will continue into the future even though the human population is expanding, economies are developing, and the oil reserves will probably be exhausted within the next century or two. Other, possibly more realistic, burning rates are considered in the modeling discussed below. The time scales for $\mathrm{CO}_{2}$ uptake differ from one process to another. For photosynthesis, the relevant uptake time is the lifetime of a growing tree, roughly 50 to 100 years. For the ocean, there are two separate time scales: the mixing time of the surface ocean (a few months) and the mixing time of the deep ocean ( 1000 years). Since most of the volume of the ocean and, hence, most of its $\mathrm{CO}_{2}$ uptake capacity, is in the deep ocean, the longer time scale is more relevant to the fossil fuel problem. The time scale for seafloor carbonate dissolution is several thousand years, because $\mathrm{CO}_{2}$-enriched seawater will probably have to circulate over these sediments several times to induce them to dissolve ${ }^{14}$. The characteristic time scale for weathering of carbonate and silicate minerals on the continents is tens to hundreds of thousands of years ${ }^{10}$.

The point of this discussion is the following: The probable $\mathrm{CO}_{2}$ release time is of the order of centuries; the $\mathrm{CO}_{2}$ uptake time is thousands to hundreds of thousands of years. In view of this mismatch, it should not be surprising that that the atmospheric $\mathrm{CO}_{2}$ concentration is increasing; moreover, it should be expected that $\mathrm{CO}_{2}$ levels will continue to increase over the next few centuries if we continue to burn fossil fuels. The next section attempts to quantify this prediction by describing a recent computer simulation of the long-term effects of fossil fuel burning.

\section{MODELING THE UPTAKE OF FOSSIL FUEL $\mathrm{CO}_{2}$}

The $\mathrm{CO}_{2}$ release and uptake processes described in the previous section can be incorporated into computer models to simulate the rise in atmospheric $\mathrm{CO}_{2}$ over the past two centuries and to try to predict future $\mathrm{CO}_{2}$ levels as a function of fossil fuel consumption and patterns of land use. Here, we describe the results from a recent modeling study by Walker and Kasting ${ }^{24}$. This study is unique in that it is the only modeling study to date that incorporates all aspects of the geochemical carbon cycle; hence, it is the only such study that is capable of tracking the fossil fuel $\mathrm{CO}_{2}$ pulse from beginning to end. It should be emphasized from the start that the detailed predictions of this, or any other, existing model are uncertain because the $\mathrm{CO}_{2}$ uptake processes are difficult to parameterize and because the computer models are, at best, highly simplified approximations to the real atmosphere-ocean system. Nonetheless, the basic nature of the predictions should be reasonably robust because the results depend to a large extent on relative reservoir sizes and approximate transfer times, both of which are fairly well understood.

The Walker and Kasting model consists of a set of 8 boxes representing the atmosphere, terrestrial biosphere (forests plus soils), warm and cold surface ocean, thermocline, and three deep ocean reservoirs (Fig. 3). The independent variables tracked by the model include atmospheric $\mathrm{CO}_{2}$ concentration, biospheric carbon content, and five quantities in each ocean box: total dissolved inorganic carbon ( $\Sigma$ $\left.\equiv\left[\mathrm{H}_{2} \mathrm{CO}_{3}\right]+\left[\mathrm{HCO}_{3}{ }^{-}\right]+\left[\mathrm{CO}_{3}{ }^{-}\right]\right)$, alkalinity $\left(\mathrm{A} \equiv\left[\mathrm{HCO}_{3}{ }^{-}\right]+2\left[\mathrm{CO}_{3}{ }^{\circ}\right]\right)$, dissolved phosphorus, and two isotopes of carbon $\left({ }^{13} \mathrm{C}\right.$ and $\left.{ }^{14} \mathrm{C}\right)$. The variables $\Sigma$ and $\mathrm{A}$ are the 


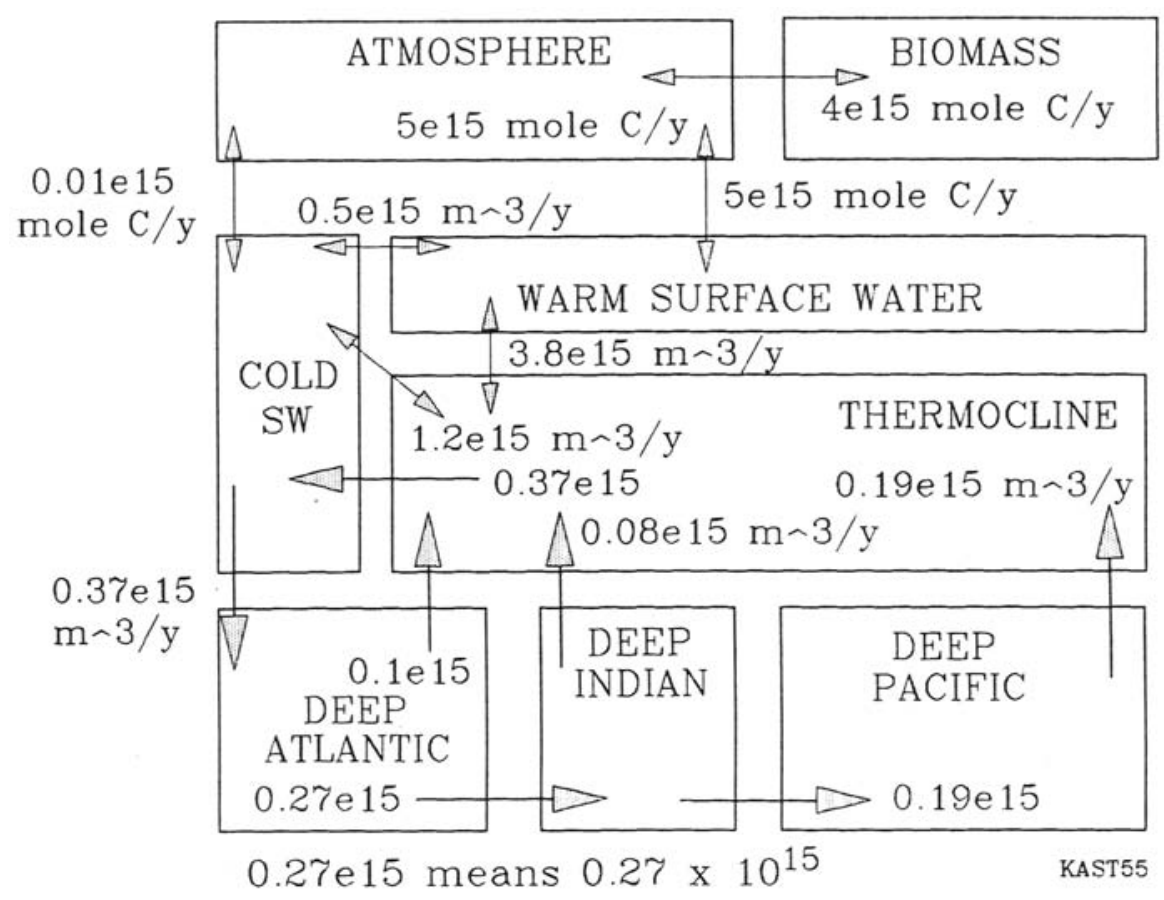

Fig. 3 Reservoirs and exchange fluxes in the Walker and Kasting box model. Exchange fluxes between the various ocean boxes are given in $\mathrm{m}^{3} / \mathrm{yr}$; fluxes between the atmosphere and other reservoirs are in moles $\mathrm{C} / \mathrm{yr}$. 1e10 means $1 \times 10^{10}$.

chemical oceanographer's way of keeping track of dissolved carbonate species. Since the concentration of carbonic acid is negligible compared to that of bicarbonate and carbonate ion at typical ocean $\mathrm{pH}$ values (7.5 to 8), one can easily demonstrate that

$$
\begin{gathered}
{\left[\mathrm{HCO}_{3}^{-}\right]=2 \mathbf{\Sigma}-\mathbf{A}} \\
{\left[\mathrm{CO}_{3}^{-}\right] \simeq A-\Sigma}
\end{gathered}
$$

Two parameters are sufficient to completely characterize the dissolved inorganic carbon species; $\Sigma$ and A happen to be the two easily measurable quantities. Phosphorus is tracked in the model because it, along with fixed nitrogen, is a limiting 
nutrient in much of the surface ocean. Thus, phosphorus availability controls the rate of organic productivity. The carbon isotopes are included as tracers of organic productivity and oceanic circulation.

In addition to the circulation fluxes shown in Figure 3, the computer model includes a flux of particulate matter from the warm surface ocean to the thermocline and deep ocean basins. The particles, which represent the remains of marine organisms, consist of a mixture of organic carbon and calcium carbonate. Most ( $>90$ percent) of these particles dissolve (or are oxidized) as they descend through the water column. As such, they constitute a 'biological pump' that tends to remove dissolved $\mathrm{CO}_{2}$ from surface water and to concentrate it in the deep ocean. This $\mathrm{CO}_{2}$ is eventually brought back up to the surface by upwelling (Fig. 3); nonetheless, an appreciable vertical gradient in $\mathrm{H}_{2} \mathrm{CO}_{3}$ concentrations is maintained by this process. Some fraction of the calcium carbonate in the descending particles survives the passage through the ocean and is buried in sediments. The amount buried depends on the carbonate saturation depth which, in this model, represents the boundary above which calcite $\left(\mathrm{CaCO}_{3}\right)$ is stable and below which it dissolves. The area of ocean floor above the carbonate saturation depth is estimated from the calculated carbonate ion content of deep water, the solubility product of calcite, and the average hypsommetry (depth-area relationship) of the ocean basins ${ }^{25}$. In the real ocean, a transition zone is observed over which the extent of dissolution of $\mathrm{CaCO}_{3}$ increases with depth and the percentage of $\mathrm{CaCO}_{3}$ in sediments decreases. That complication is ignored in the model.

Finally, the model also includes a simplified representation of the rock cycle. The magnitude of the present silicate and carbonate weathering rates (reactions 4 and 9) is estimated from the data of Meybeck ${ }^{26}$. The rate of carbonate weathering is assumed to vary linearly with $\mathrm{pCO}_{2}$; the silicate weathering is assumed to vary as $\mathrm{pCO}_{2}{ }^{0.3}$. The $\mathrm{CO}_{2}$ dependence of the silicate weathering rate is intermediate between that of Berner et al. ${ }^{10}$ and Walker et al. ${ }^{20}$. The assumption of a linear $\mathrm{CO}_{2}$ dependence for carbonate weathering is made so as to maximize the rate of uptake of fossil fuel $\mathrm{CO}_{2}$. These weathering rate laws incorporate the idea that both surface temperature and possibly global runoff rates increase with increasing atmospheric $\mathrm{CO}_{2}$, and that the combination of these factors tends to accelerate rates of chemical weathering.

After adjusting the oceanic circulation rates and particle fluxes to try to match the present system as closely as possible, the model was used to simulate the observed rise in atmospheric $\mathrm{CO}_{2}$ during the past two centuries (Fig. 4). The boxes in Figure 4 show (annually averaged) $\mathrm{CO}_{2}$ measurements from Mauna Loa; the crosses and triangles represent measured values derived from air bubbles trapped in ice cores, ${ }^{4,5}$. The dashed curve is the fossil fuel burning rate; the solid curve shows atmospheric $\mathrm{CO}_{2}$ concentrations projected by the model. Although the model correctly predicts the overall increase in atmospheric $\mathrm{CO}_{2}$, the shape of the curve does not agree with the measurements: the predicted rate of $\mathrm{CO}_{2}$ increase between 1850 and 1950 is too slow, whereas the rate of increase since that time is too fast.

Part of the reason for the discrepancy is well understood ${ }^{27,28}$. Much of the observed atmospheric $\mathrm{CO}_{2}$ increase between 1850 and 1950 is thought to have been caused by the clearing of forests in the northern hemisphere and in the tropics, rather 


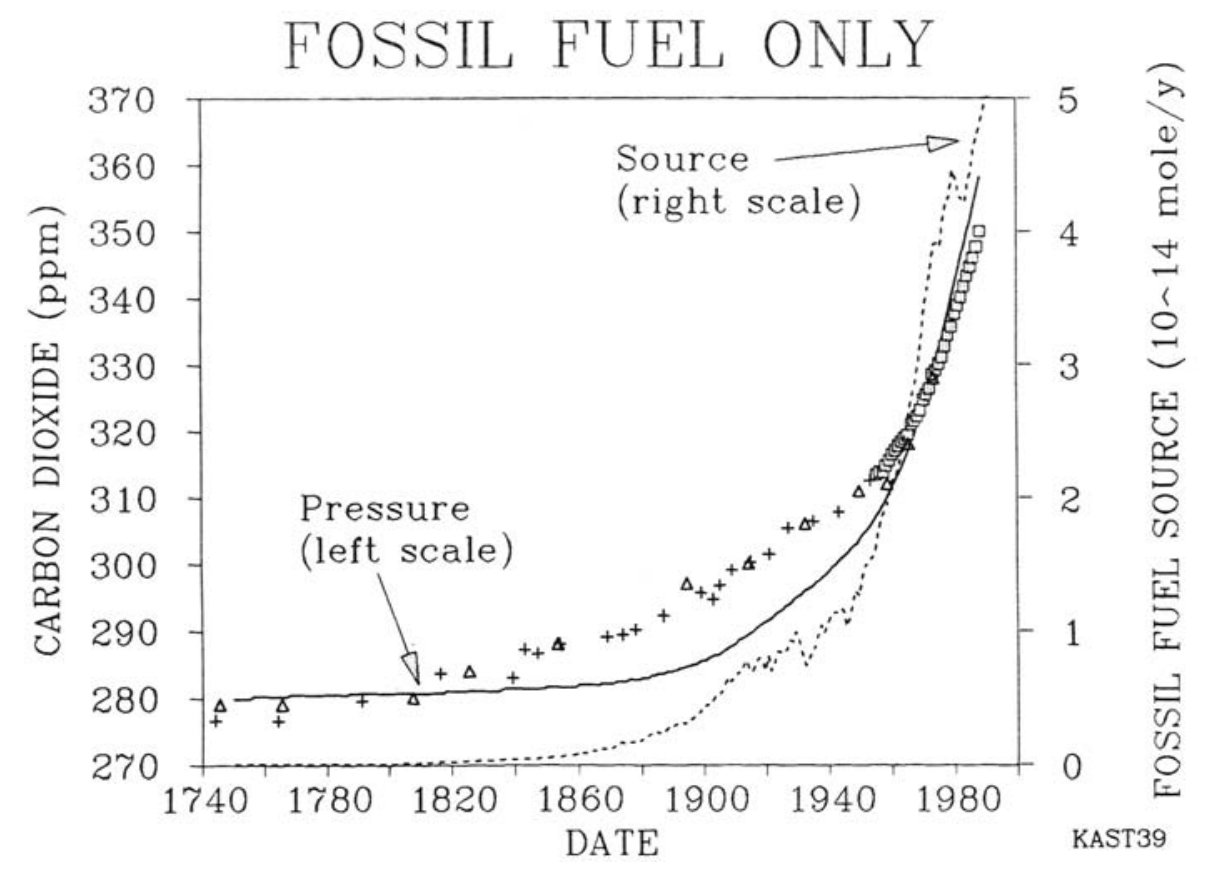

Fig. 4 History of atmospheric $\mathrm{CO}_{2}$ during the last two centuries. Boxes denote annually-averaged measurements from Mauna Loa; triangles and crosses represent measurements of air bubbles trapped in polar ice. The dashed curve is the fossil fuel source, given by the right-hand scale. The solid curve shows the predictions of the box model when only the fossil fuel $\mathrm{CO}_{2}$ source is included.

than by the burning of fossil fuels. This process is called the 'pioneer effect' in reference to the activities of colonial pioneers. Estimates of the rates of carbon release by deforestation during this time have been compiled by different authors ${ }^{29,30}$. They are shown here in Figure 5, along with a quantity termed 'biomass potential' ${ }^{24}$. Biomass potential is defined as normalized forest area, weighted by carbon storage; it is given a value of unity for the preindustrial Earth.

Including this additional anthropogenic $\mathrm{CO}_{2}$ source in the model produces the results shown in Figure 6. Making this change brings the model into agreement with the ice core data up until about the year 1860 A.D. After this time, however, the model predicts much higher levels of atmospheric $\mathrm{CO}_{2}$ than were actually observed. This is a problem that is common to all carbon cycle models (e.g. refs. 27 and 28): 


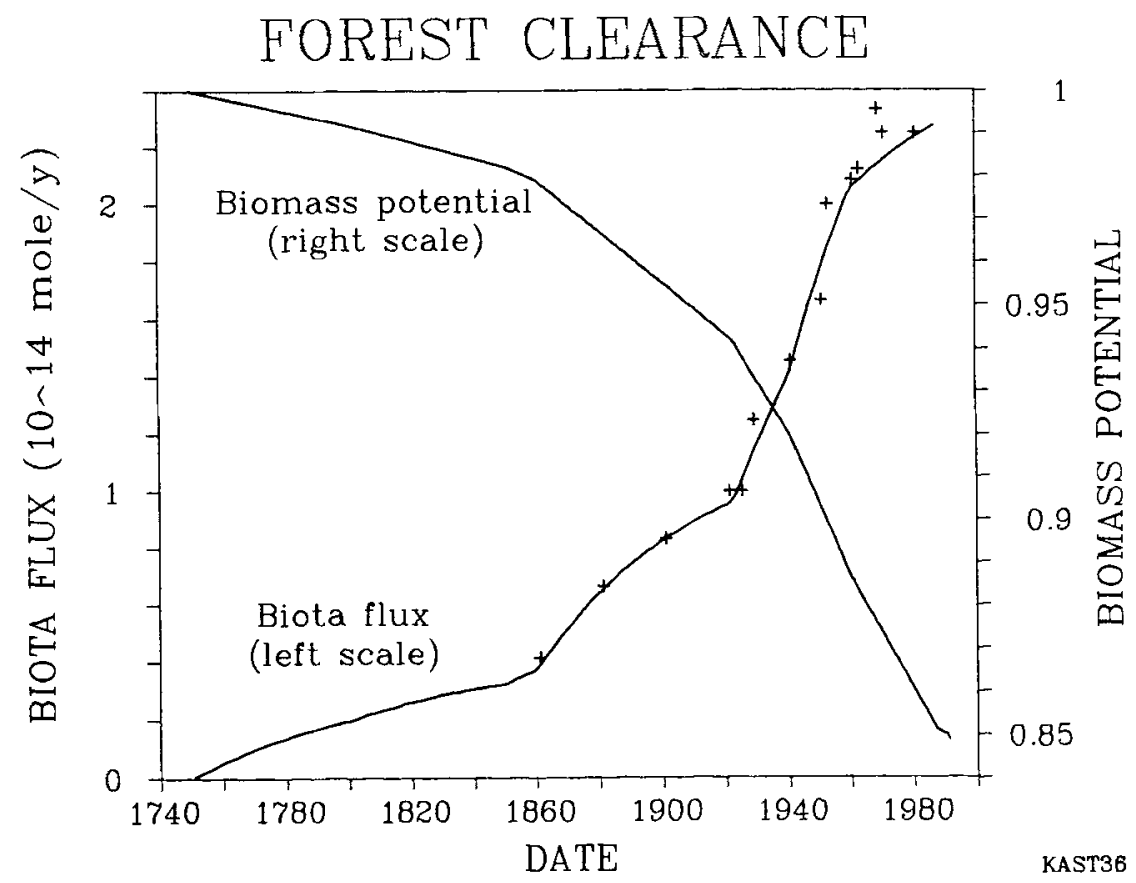

Fig. 5 The historical flux of carbon from the biota to the atmosphere caused by changes in land use. The crosses represent values deduced from land use studies. The quantity called 'biomass potential' (defined in the text) represents the amount of carbon stored in forests and soils, normalized to the preindustrial value. The preindustrial value is estimated from the biota flux.

there is evidently a missing sink for $\mathrm{CO}_{2}$. The same problem is encountered when one tries to make an accurate accounting of the present global budget of atmospheric $\mathrm{CO}_{2}{ }^{31}$. The most likely solution to the missing carbon problem involves a recent increase in the amount of carbon stored in temperate and boreal forests.

One reason that carbon storage in forests might be increasing is because $\mathrm{C} 3$ plants (which include most trees) grow faster under enhanced $\mathrm{CO}_{2}$ levels. $\mathrm{C} 4$ plants, such as corn and most grasses, are much less sensitive to $\mathrm{CO}_{2}$. (The terms ' $\mathrm{C} 3$ ' and 'C4' refer to the number of carbon atoms fixed in the primary photosynthetic step.) For C3 plants grown under controlled, greenhouse conditions, the relative growth rate can be approximated by the function ${ }^{32}$

$$
F\left(\mathrm{CO}_{2}\right)=2.22\left(1-\exp \left[-0.003\left(\mathrm{pCO}_{2}-80\right)\right]\right)
$$




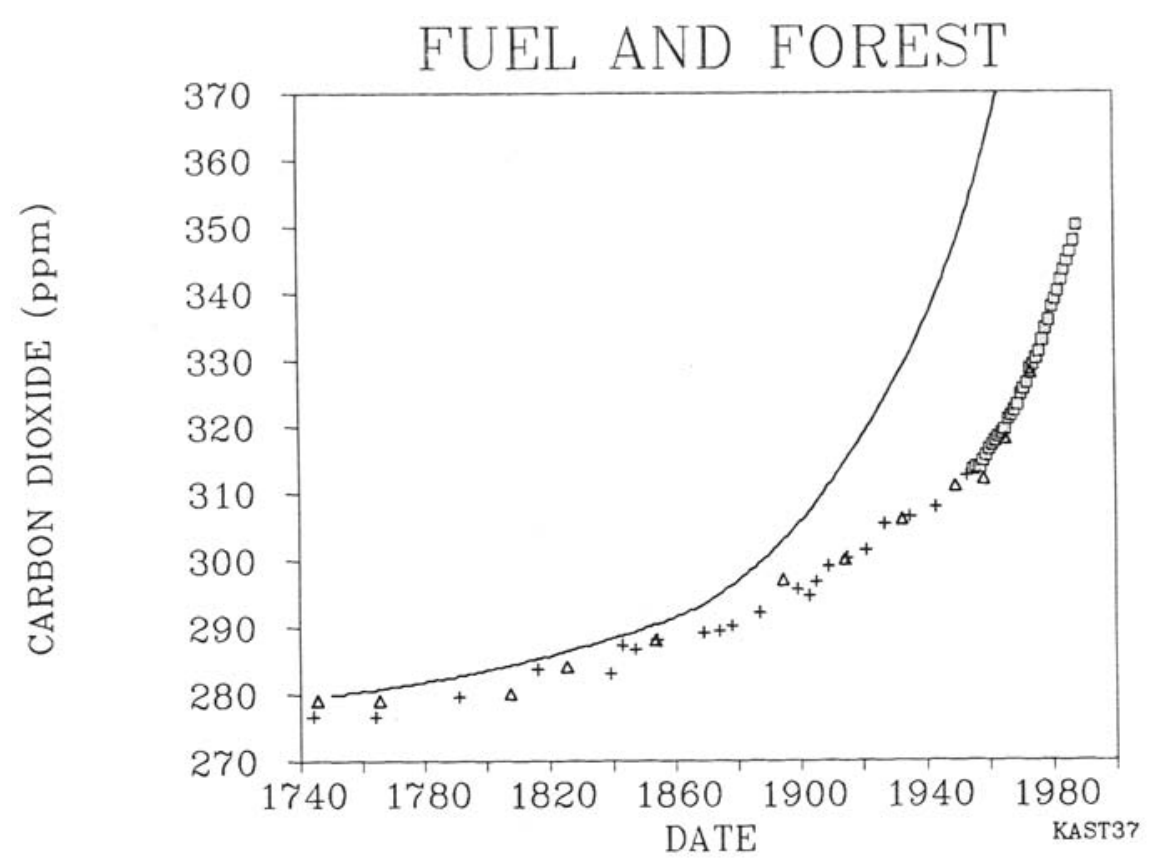

Fig. 6 Atmospheric $\mathrm{CO}_{2}$ concentrations calculated when the estimated biota flux from land use changes (Fig. 5) is included in the box model.

This function has been adjusted to yield a relative growth rate of unity at the preindustrial $\mathrm{CO}_{2}$ level of $280 \mathrm{ppm}$. Note that the growth rate drops to zero at a $\mathrm{CO}_{2}$ level of $80 \mathrm{ppm}$. This is the compensation point, below which many plants respire faster than they photosynthesize. Whether or not this same fertilization function applies to natural ecosystems, where factors other than $\mathrm{CO}_{2}$ availability may limit the growth rate, is a matter of current debate.

Adding $\mathrm{CO}_{2}$ fertilization to the model allows it to reproduce the historical trend in atmospheric $\mathrm{CO}_{2}$ levels reasonably well (Fig. 7). This does not, of course, prove that $\mathrm{CO}_{2}$ fertilization is the correct explanation for the missing $\mathrm{CO}_{2}$ sink or that this effect will continue in the future. Let us assume for the moment, however, that $\mathrm{CO}_{2}$ fertilization is real and operative. One can then use the model to predict future atmospheric $\mathrm{CO}_{2}$ levels for different assumptions concerning rates of fossil fuel consumption and patterns of deforestation/reforestation. Some possible scenarios are shown in Figure 8. In the 'save fuel' scenario (bottom panel) the present rate of fossil fuel burning, $5 \times 10^{14}$ moles $\mathrm{C} \mathrm{yr}^{-1}$, is assumed to continue for the next 700 years until 


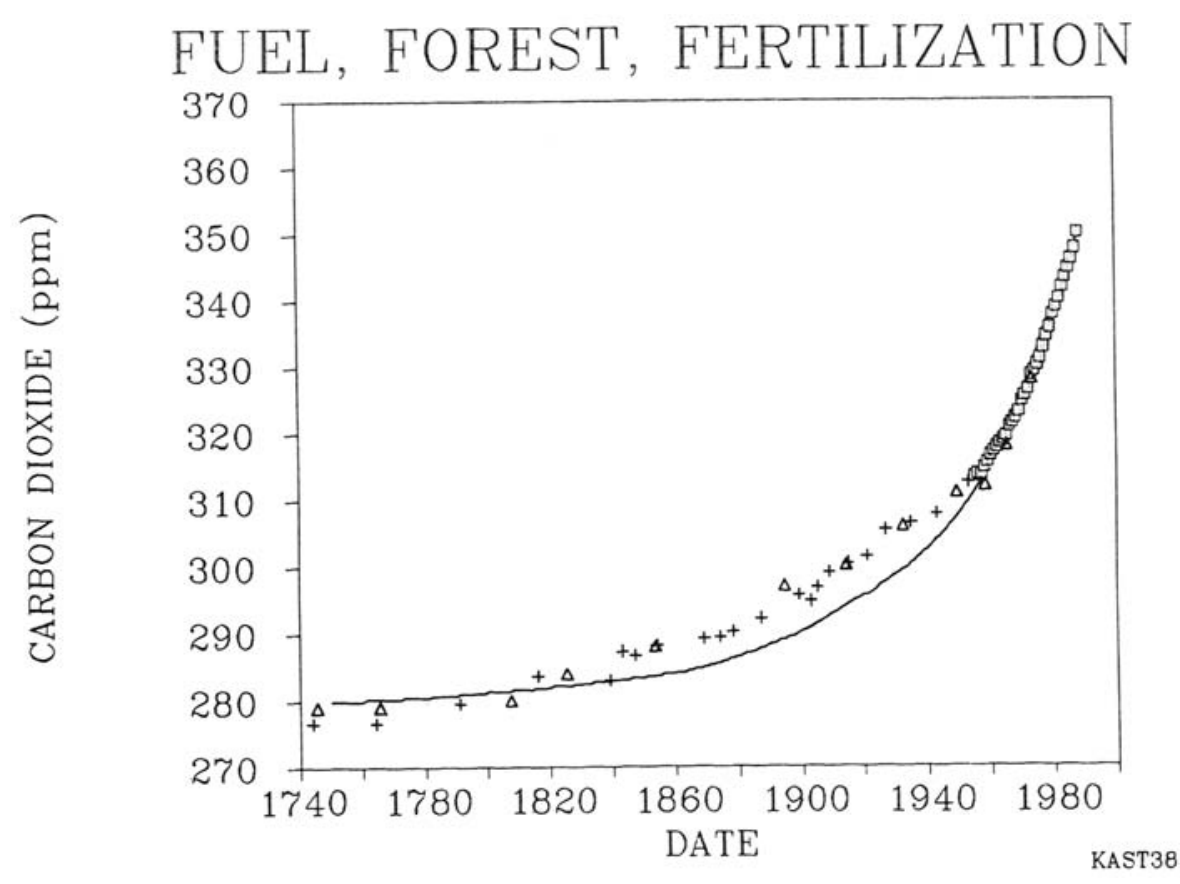

Fig. 7 Atmospheric $\mathrm{CO}_{2}$ concentrations calculated when both the biota flux and the $\mathrm{CO}_{2}$ fertilization effect are included in the box model.

the entire $35 \times 10^{16}$ moles of carbon in the 1982 recoverable reserves are exhausted. The 'burn fuel' scenario assumes that the same total amount of fossil fuel is consumed in less than 400 years. The 'save forests' scenario (upper panel) assumes that deforestation ceases immediately and that the areal extent of forests remains constant into the indefinite future. The 'burn forests' scenario assumes that the present trend of deforestation continues until only 30 percent of the original, preindustrial forest area remains.

The various combinations of the above assumptions yield four different cases that were examined with the model (Fig. 9). The most pessimistic (but, arguably, the most realistic) of these is represented by the scenario labelled 'burn both,' in which the fossil fuels are burned rapidly and the forests are assumed to disappear. Atmospheric $\mathrm{CO}_{2}$ concentrations are predicted to reach $\sim 2100 \mathrm{ppm}$ in this case; the peak occurs in about the year 2350 A.D. when the fossil fuel reserves are nearly exhausted. Somewhat surprisingly, the 'burn forests, save fuel' results are not tremendously different: atmospheric $\mathrm{CO}_{2}$ peaks at $\sim 2000$ ppm in the year 2700 . 


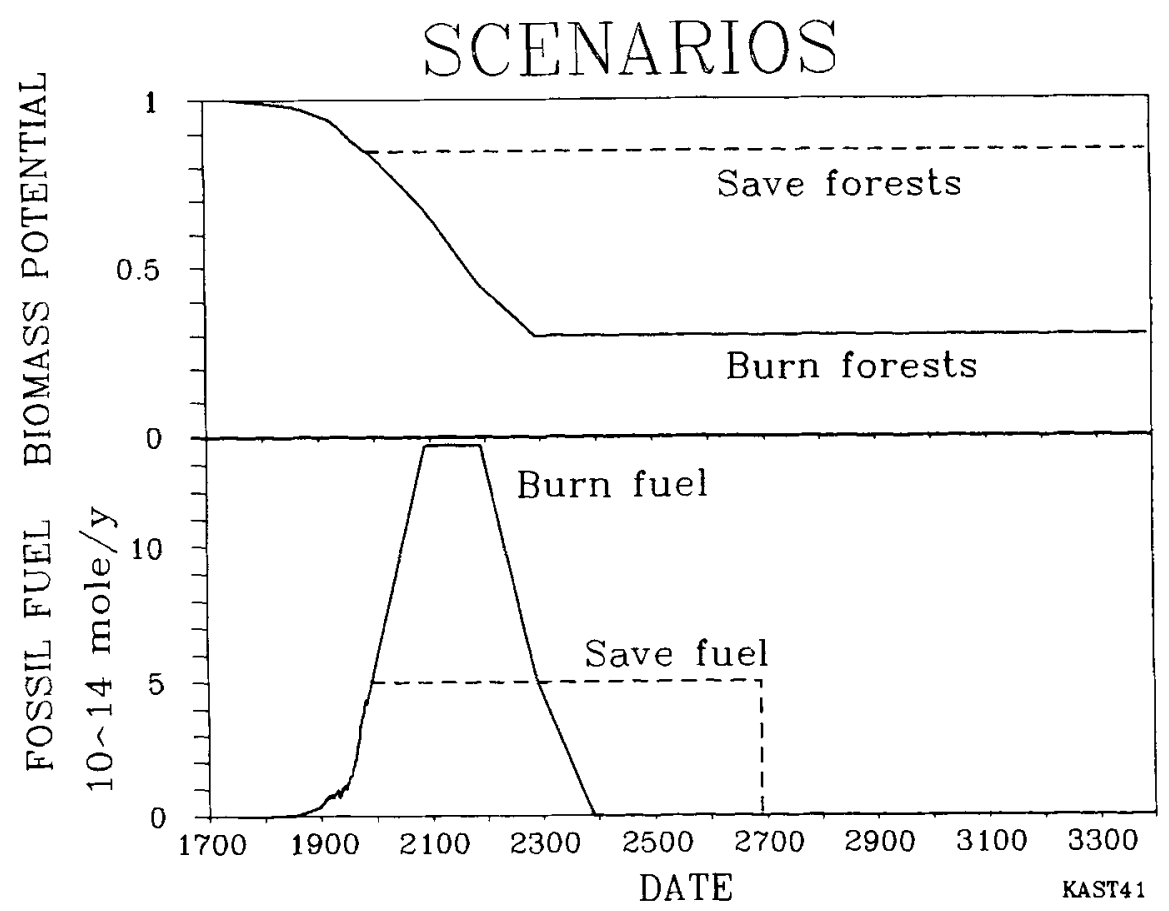

Fig. 8 Hypothetical scenarios for future rates of fossil fuel burning and patterns of land use. The 'save fuel' curve corresponds to burning the existing fossil fuel reserves at the present rate. The total amount of fossil fuel consumed is the same in both cases.

Burning the fossil fuels at a slower rate delays the $\mathrm{CO}_{2}$ increase by $300-400$ years but does little to diminish its eventual magnitude. Given a little additional thought, this result is not so surprising after all. In both cases, the time scale for $\mathrm{CO}_{2}$ input is significantly shorter than the time scale for $\mathrm{CO}_{2}$ removal. A significant decrease in the present fossil fuel consumption rate would be needed to reduce the magnitude of the atmospheric $\mathrm{CO}_{2}$ peak.

What is remarkable in this model is the large reduction in future atmospheric $\mathrm{CO}_{2}$ levels that results from preserving the forests. The two lower curves in Figure 9 indicate that the peak $\mathrm{CO}_{2}$ level is reduced to $\sim 1100 \mathrm{ppm}$ in both the 'burn fuel' and 'save fuel' scenarios. Roughly $1000 \mathrm{ppm}$ of $\mathrm{CO}_{2}$, or three times the amount now present in the atmosphere, has been absorbed by the biomass reservoir as a consequence of $\mathrm{CO}_{2}$ fertilization. Examination of Table 1 shows that this implies a doubling of the total amount of carbon stored in forests and soils. $\mathrm{CO}_{2}$ fertilization 


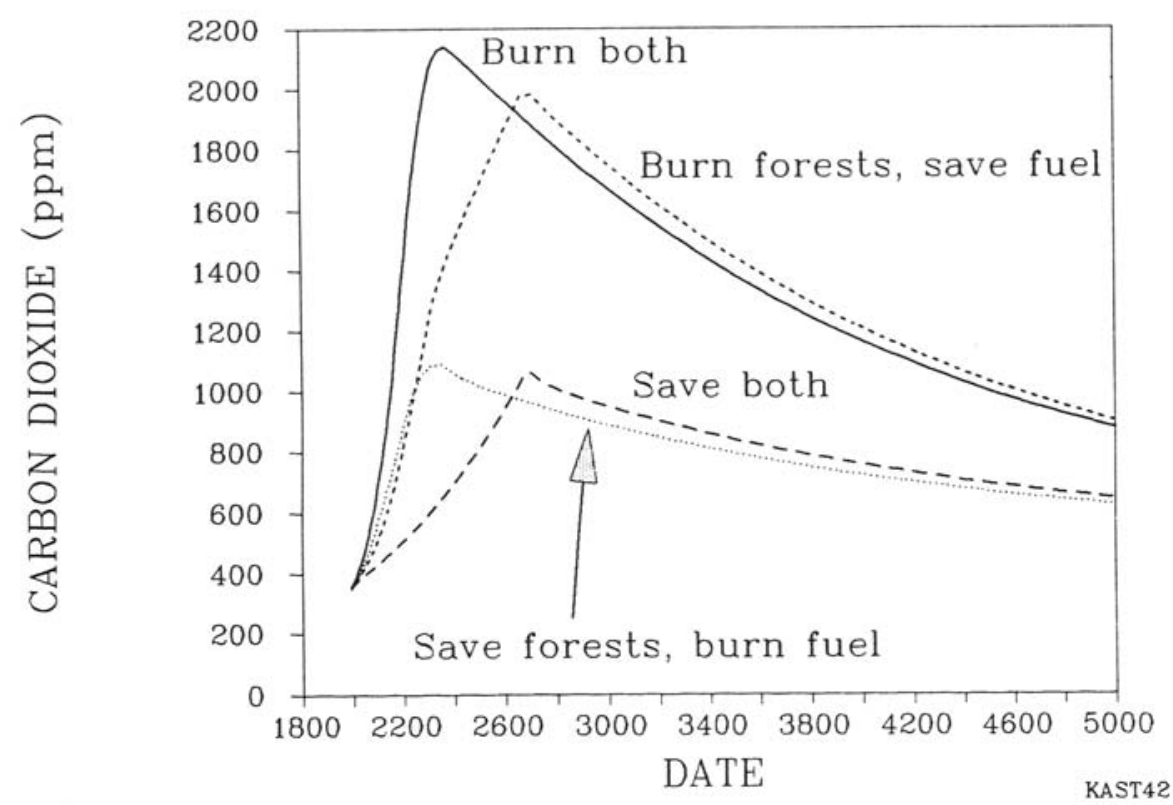

Fig. 9 Atmospheric $\mathrm{CO}_{2}$ concentrations predicted by the box model for the different scenarios shown in Fig. 8. All of these calculations assume that $\mathrm{CO}_{2}$ fertilization is real and will continue to affect growth rates in the future.

is also assumed to apply in the 'burn forests' scenarios, but its effect on atmospheric $\mathrm{CO}_{2}$ is much smaller because of the smaller area of forested land.

Taken at face value, these results would seem to indicate that preserving the forests is more important in the long term than is conserving fossil fuel. This conclusion may be premature, however, for two reasons: First, as mentioned earlier, $\mathrm{CO}_{2}$ fertilization may be less effective for natural ecosystems than it is in a controlled, greenhouse environment. Second, even if trees do grow faster in a high- $\mathrm{CO}_{2}$ environment, it is not obvious that soil carbon storage will increase proportionately. Indeed, Houghton and Woodwell ${ }^{15}$ have argued (convincingly, we believe) that soil carbon storage will likely decrease as the climate warms. Their prediction is based partly on the observation that tropical soils today contain much less carbon than do soils in temperate and boreal ecosystems. The reason is that organic material decays much faster in a warm climate. Thus, if global warming converts temperate ecosystems into subtropical ones, much of the organic carbon stored in these soils could be returned to the atmosphere.

This phenomenon is crudely simulated in the computer model by increasing 
the decay rate of biomass by a factor of two for a $10^{\circ} \mathrm{C}$ rise in surface temperature. The model predicts that global surface temperatures will rise about $2^{\circ} \mathrm{C}$ for each doubling of atmospheric $\mathrm{CO}_{2}$; hence, the maximum temperature increase for the scenarios considered in Figure 9 is about $6^{\circ} \mathrm{C}$. The corresponding increase in the decay rate is $2^{0.6}$, or a factor of roughly 1.5 . Including this 'enhanced decay' rate assumption in the model yields the results shown in Figure 10. The curves shown are for the 'save forests, burn fuel' scenario; the terms 'enhanced growth' and 'constant growth' indicate whether or not $\mathrm{CO}_{2}$ fertilization has been included in the calculation. It can be seen from Figure 10 that the beneficial effects of preserving the forests are greatly diminished when either the fertilization effect is eliminated or the decay rate is enhanced. Only an optimist would conclude that forests will save us from the most pronounced effects of fossil fuel burning.

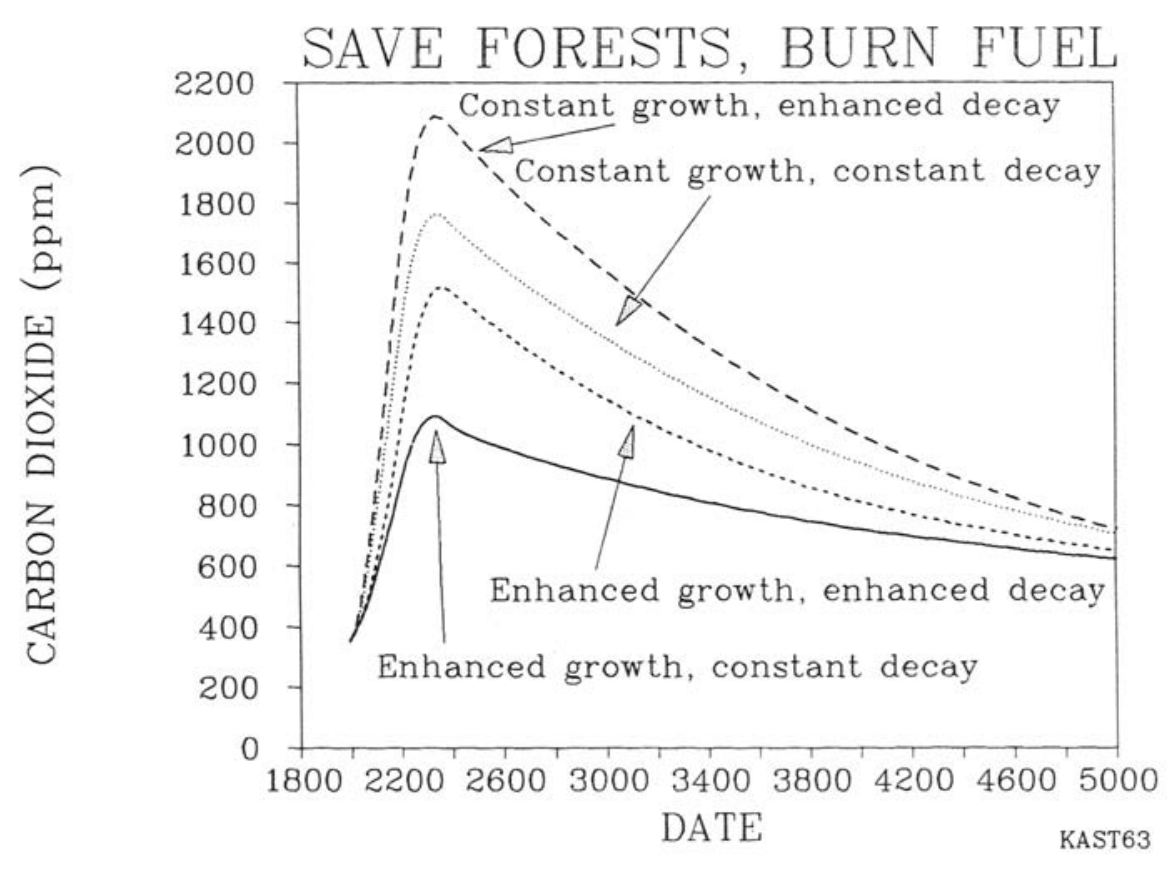

Fig. 10 Predicted atmospheric $\mathrm{CO}_{2}$ concentrations for the 'save forests, burn fuel' scenario of Fig. 9, but with various assumptions concerning $\mathrm{CO}_{2}$ fertilization and soil carbon decay rates. The solid curve is the same as in Fig. 9; the other curves show the effects of suppressing $\mathrm{CO}_{2}$ fertilization and/or increasing the decay rate. 
The discussion at this stage has evolved away from the geochemical carbon cycle and towards the biological carbon cycle. But the geochemical cycle underlies all of these future $\mathrm{CO}_{2}$ projections in a fundamental way. This point is brought out by the last three figures. Figure 11 shows the near-term effect of assuming different fossil fuel consumption rates in the Walker and Kasting ${ }^{24}$ model. The solid curve is for the 'burn fuel' scenario of Figure 8; the dashed curves are for a constant burning rate of $5 \times 10^{14}$ moles $\mathrm{C} \mathrm{yr}^{-1}$ (the current value) and for immediate decreases of 20 percent and 50 percent from that value. All curves are for the optimistic, 'enhanced growth, constant decay' scenario of Figure 10.

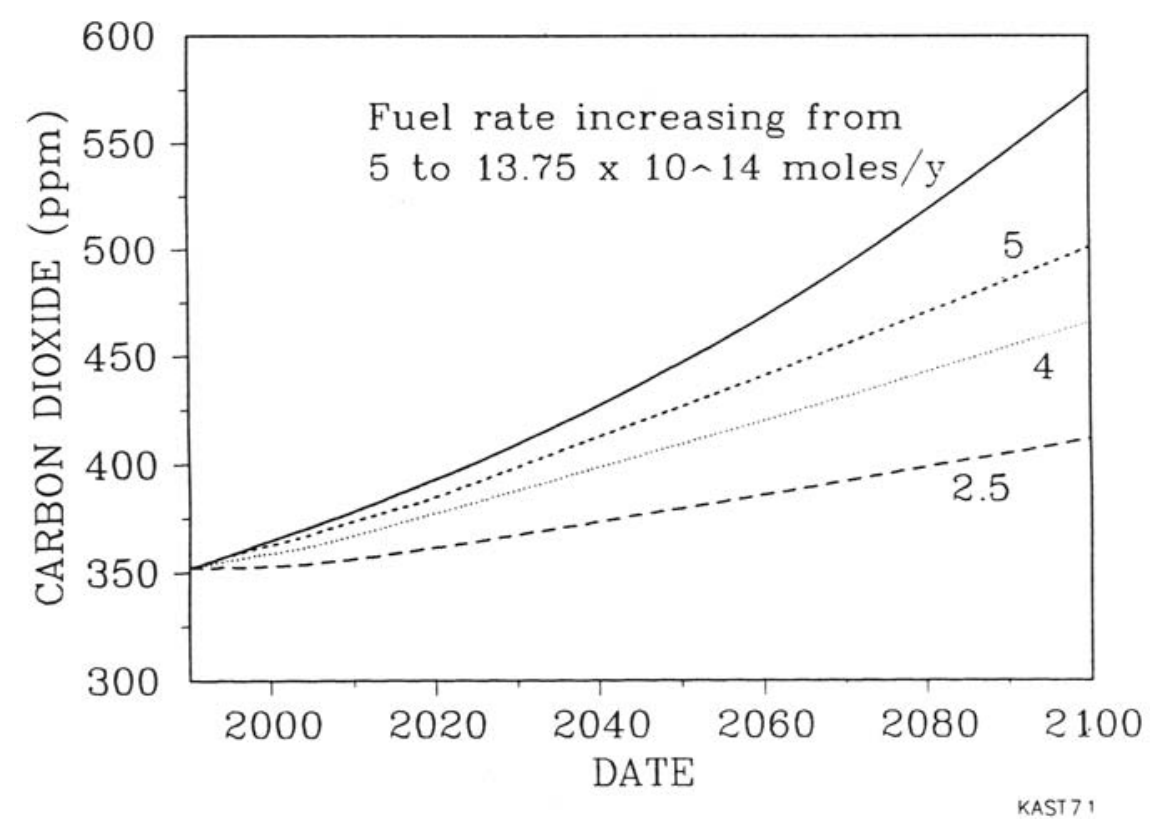

Fig. 11 Predicted atmospheric $\mathrm{CO}_{2}$ concentrations during the next century for the 'save forests' scenario with various assumed rates of fossil fuel burning: 1) solid curve -- 'burn fuel' scenario from Fig. 8; 2) short dashes -- present burning rate; 3 ) dots -- 80 percent of the present burning rate; 4) long dashes - 50 percent of the present rate. $\mathrm{CO}_{2}$ fertilization is included in all of these calculations.

The results indicate that modest decreases in fossil fuel consumption cannot stabilize atmospheric $\mathrm{CO}_{2}$, contrary to statements that have occasionally appeared in the literature. Such decreases can, however, slow the rate of global warming. According to this model, a 20 percent reduction in fossil fuel emissions produces a 23 percent 
reduction in the rate of $\mathrm{CO}_{2}$ increase; a 50 percent emissions reduction produces a 60 percent reduction in the rate of $\mathrm{CO}_{2}$ increase. The effect is thus slightly nonlinear; one gets proportionately more benefit from large emission rate reductions than from small ones. But an anthropogenic emission rate of half the present value is still more than enough to overwhelm the natural carbon cycle over the next century.

Figure 12 shows the longer-term effect of even more drastic decreases in the fossil fuel burning rate. The assumption, as before, is that the total amount of fossil fuel consumed is $35 \times 10^{16}$ moles; the assumptions concerning forests are the optimistic ones described above. The slowest burning rate considered (solid curve) represents an immediate, 25 -fold decrease in the rate of fossil fuel burning.

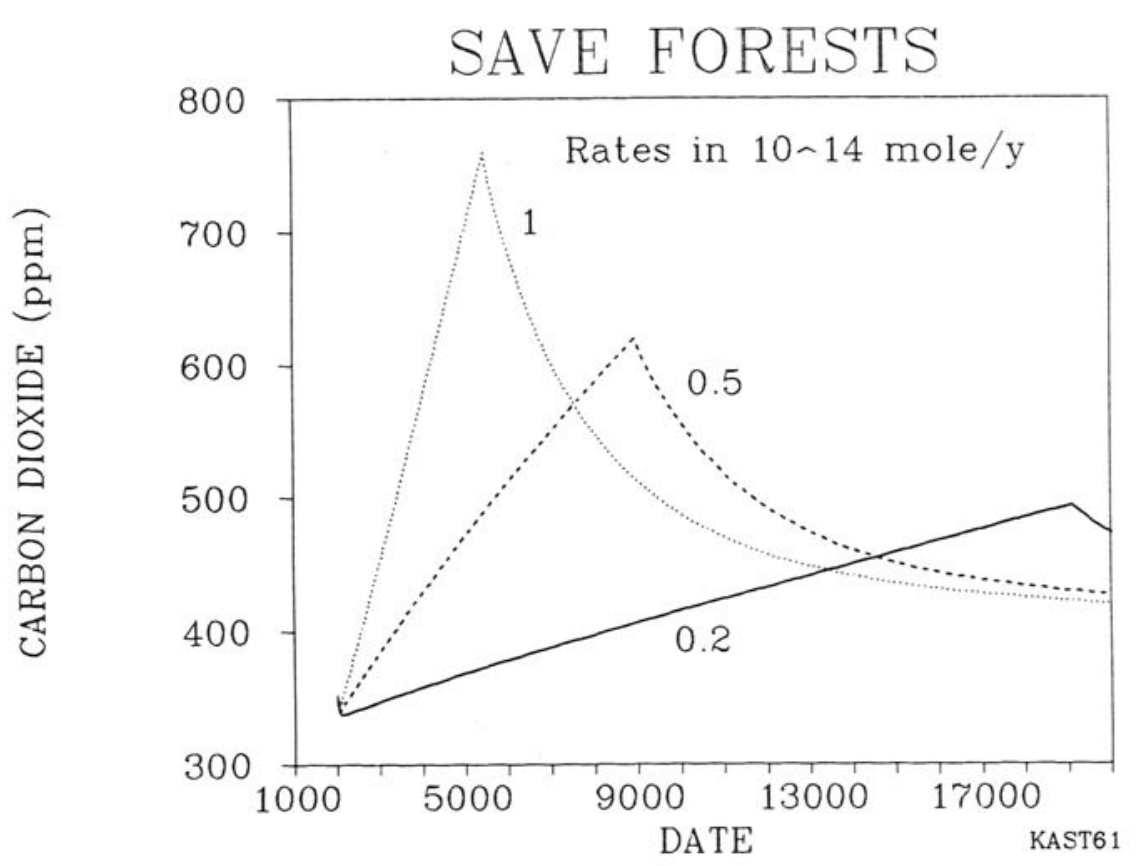

Fig. 12 As in Fig. 11, but with substantially lower rates of fossil fuel burning. The total amount of fossil fuel consumed is fixed at $35 \times 10^{16}$ moles; the burning rate ranges from $1 / 5$ to $1 / 25$ of the present value.

Even in this case, atmospheric $\mathrm{CO}_{2}$ concentrations increase to $\sim 500 \mathrm{ppm}$ before beginning to decline. The peak $\mathrm{CO}_{2}$ level occurs 17,000 years in the future, which is sufficiently far off that we might not worry about it very much. However, the calculation illustrates an important point: atmospheric $\mathrm{CO}_{2}$ concentrations should 
continue to rise as long as the rate of anthropogenic $\mathrm{CO}_{2}$ input exceeds, or is comparable to, the natural input of $\mathrm{CO}_{2}$ to the atmosphere-ocean system. The natural $\mathrm{CO}_{2}$ source, as discussed earlier, is volcanic outgassing; its magnitude is roughly 100 times less than the present rate of fossil fuel burning. Burning fossil fuels at even a few percent of the present rate should therefore be enough to keep atmospheric $\mathrm{CO}_{2}$ levels on the rise.

A second point that was made earlier is the long time scale required for the geochemical $\mathrm{CO}_{2}$ removal processes to be effective. This point is illustrated in Figure 13, which shows the recovery of the atmosphere-ocean system to its assumed preindustrial steady state. (The long time-scale simulation is made possible by using

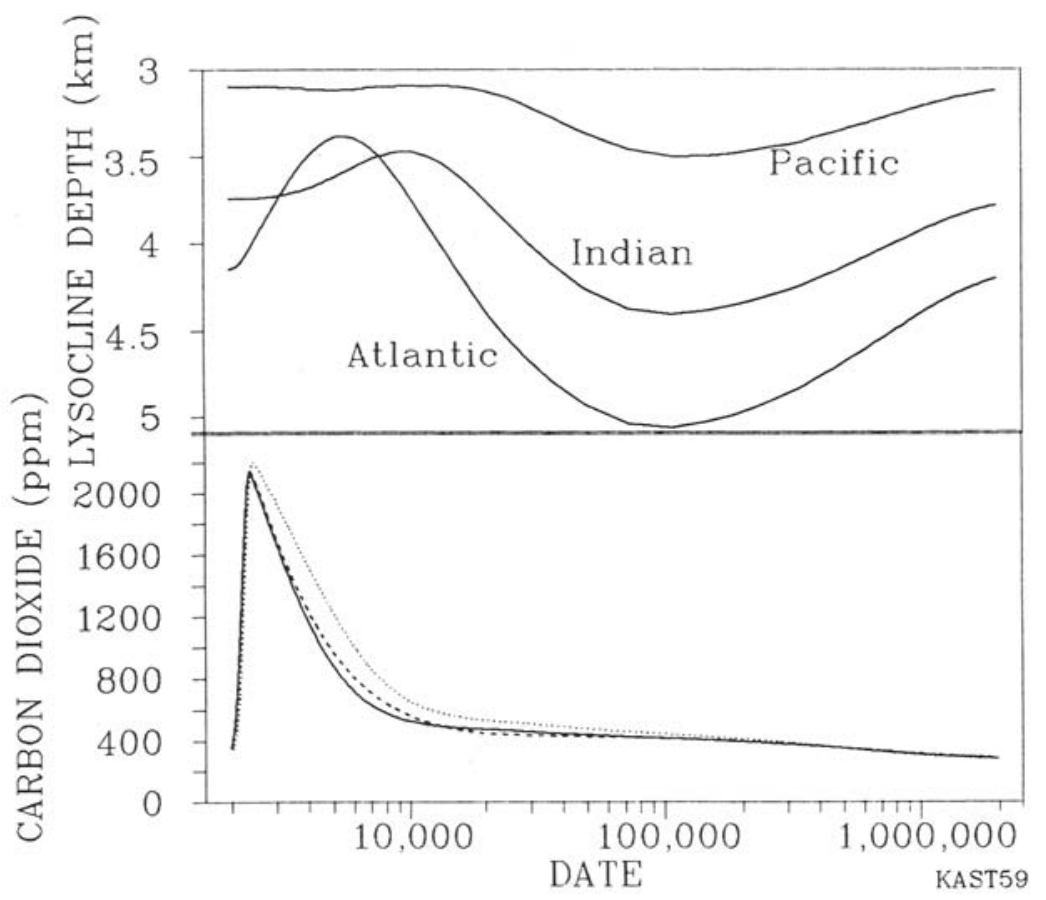

Fig. 13 The long-term recovery of atmospheric $\mathrm{CO}_{2}$ after the injection of fossil fuel and forest carbon in the 'burn both' scenario of Fig. 9. The solid curve is the standard model; the dashed curved shows the effect of suppressing seafloor carbonate dissolution; the dotted curve assumes a carbonate weathering rate that is less sensitive to increases in atmospheric $\mathrm{CO}_{2}$. The upper panel shows the calculated depth of the lysocline in the three deep ocean basins for the standard case. 
an implicit integration method. ${ }^{33}$ ) The solid curve in the bottom panel shows atmospheric $\mathrm{CO}_{2}$ levels predicted for the pessimistic, 'burn both' scenario of Figure 9. The other curves show the consequences of suppressing seafloor carbonate dissolution (dashed curve) or assuming a weaker, square-root, dependence of the carbonate weathering rate on atmospheric $\mathrm{CO}_{2}$ (dotted curve). In each case, the bulk of the anthropogenic $\mathrm{CO}_{2}$ is removed within a few thousand years. The important processes on this time scale are neutralization of dissolved carbonate ion (reaction 8), dissolution of seafloor carbonate sediments, and weathering of carbonate rocks on land (both represented by reaction 9). During this time, the carbonate saturation (or 'lysocline') depth moves up, especially in the Atlantic where the deep water is forming. But the system cannot return all the way to steady state as a consequence of these processes alone. The ocean at this stage contains an excess of bicarbonate ion produced from reactions (8) and (9). The only way it can lose this bicarbonate is by an increase in silicate weathering on the continents (reaction 4) caused by higher atmospheric $\mathrm{CO}_{2}$, followed by excess deposition of carbonate sediments on the seafloor (reaction 5). The results of the weathering rate increase are manifested by an increase in deep ocean alkalinity and a corresponding deepening of the carbonate saturation depth. The deepening saturation depth allows carbonate sediments to be deposited over a greater area of the ocean floor; this increased deposition, in turn, finally removes the excess anthropogenic $\mathrm{CO}_{2}$. The entire process requires more than a million years because it is limited by the slow rate of weathering of silicate rocks.

Once again, it should be emphasized that the details of the $\mathrm{CO}_{2}$ uptake processes are poorly understood. Thus, the precise shapes of the curves shown in Figure 13 are subject to considerable uncertainty. If global temperatures increase more than assumed in the model, or if the rate of silicate weathering increases more rapidly with higher atmospheric $\mathrm{CO}_{2}$, the long-term recovery of the system may be faster than shown here. On the other hand, if deep ocean circulation rates decrease, or if carbonate sediments dissolve more slowly than assumed, the decline of the fossil fuel $\mathrm{CO}_{2}$ pulse may be significantly delayed. In spite of these uncertainties, it is safe to conclude that it will take thousands to hundreds of thousands of years for atmospheric $\mathrm{CO}_{2}$ to return to its preindustrial level if we consume most of the available fossil fuels. Whether the actual recovery time lies towards the short or long end of this window is a question of mainly academic interest.

\section{IMPLICATIONS FOR FUTURE ENERGY AND LAND USE POLICY}

The implications of our model results for future global energy and land use policy are clear. Energy conservation can buy us time, but it cannot by itself prevent global warming. The required reductions in $\mathrm{CO}_{2}$ emissions are simply too large. If we wish to avoid the excessive atmospheric $\mathrm{CO}_{2}$ increases seen in Figures 9 and 13, it will be necessary to reduce the rate of fossil fuel consumption to at most a few percent of the present value. Preserving existing forests, or reforesting areas that were previously cleared, could help to take up some of the fossil fuel $\mathrm{CO}_{2}$; however, one should not count on this to alleviate global warming because the net transfer of carbon between the atmosphere and the biosphere could very easily go in the wrong direction. 
Exactly how one might implement these suggestions is not at all clear. If we are to stop consuming fossil fuels, we will need to develop alternative energy sources and we may have to change our lifestyles. Ideally, $\mathrm{CO}_{2}$ emissions could be reduced or eliminated simply by encouraging energy conservation and by exploiting renewable energy sources such as solar, wind, and hydro power. More realistically, we may need to rely heavily on nuclear power for the next few decades and on new technologies (satellite solar power, solar-hydrogen systems, fusion?) for the period beyond that. Satellite solar power may be the best bet. In addition to being inexhaustible and non-polluting, satellite solar energy could be beamed down anywhere on Earth, including those developing countries that are projected to account for a major fraction of future $\mathrm{CO}_{2}$ emissions. Developing this resource would require a substantial international commitment of time, money, and creative thinking.

\section{CONCLUSION}

Over long time scales the $\mathrm{CO}_{2}$ content of the atmosphere is controlled by the geochemical carbon cycle, in which carbon dioxide is exchanged between the atmosphere, the ocean, and carbonate rocks. The basic outlines of this cycle are reasonably well understood and have been used to explain why atmospheric $\mathrm{CO}_{2}$ levels may have varied in response to past changes in solar luminosity and to variations in seafloor spreading rates. Some progress has been made toward understanding why atmospheric $\mathrm{CO}_{2}$ levels varied during the past glacial/interglacial cycle.

The same processes that control the atmospheric $\mathrm{CO}_{2}$ content on long time scales will be involved in the removal of $\mathrm{CO}_{2}$ produced by human activities. Comparing the present fossil fuel consumption rate with the volcanic outgassing rate of $\mathrm{CO}_{2}$ shows that humans are currently overwhelming the natural $\mathrm{CO}_{2}$ source by a factor of $\sim 100$. Atmospheric $\mathrm{CO}_{2}$ levels should continue to rise as long as this imbalance continues. Because the amount of carbon in recoverable fossil fuels is much larger than the amount in the atmosphere, and because the removal processes for $\mathrm{CO}_{2}$ are much slower than the rate at which $\mathrm{CO}_{2}$ is being produced, atmospheric $\mathrm{CO}_{2}$ could conceivably increase by a factor of six or more during the next few centuries. The eventual magnitude of the increase is only weakly dependent on the fossil fuel burning rate, unless the burning rate can be reduced to only a few percent of the present value. Forests could play an important role in taking up fossil fuel $\mathrm{CO}_{2}$, but only if forested lands are preserved, $\mathrm{CO}_{2}$ fertilization is important, and soil carbon storage increases as the forests grow. Most of the $\mathrm{CO}_{2}$ produced by human activities will be removed from the atmosphere within the next few thousand years, but the combined atmosphere-ocean system may require hundreds of thousands of years to return to its preindustrial steady state. Prudence would suggest that we halt the experiment before we find out if this prediction is correct. 


\section{ACKNOWLEDGEMENTS}

This work was supported in part by NASA Grant NAGW-176 to the University of Michigan.

\section{REFERENCES}

1. C. D. Keeling, R. B. Bacastrow, A. F. Carter, S. C. Piper, T. P. Whorf, M. Heimann, W. G. Mook and H. Roeloffzen, in Aspects of Climate Variability in the Pacific and the Western Americas, ed. by D. H. Peterson (Amer. Geophys. Union, Washington, D.C., 1989), pp. 165-236.

2. M. Trexler, The biological carbon cycle, (American Physical Society), this volume.

3. J. M. Barnola, D. Raynaud, Y. S. Korotkevich and C. Lorius, Nature $\underline{329}$, 408-414 (1987).

4. H. Friedli, H. Lotscher, H. Oeschger, U. Siegenthaler and B. Stauffer, Nature $\underline{324}$, 237-238 (1986).

5. A. Neftel, E. Moor, H. Oeschger and B. Stauffer, Nature 315, $45-47$ (1985).

6. W. S. Broecker and T.-H. Peng, Global Biogeochemical Cycles 3, 215-239 (1989).

7. W. S. Broecker, Glacial-to-interglacial $\mathrm{CO} 2$ variations (American Physical Society), this volume.

8. B. N. Opdyke and J. C. G. Walker, The return of the coral reef hypothesis: Glacial to interglacial partitioning of basin to shelf carbonate and its effect on Holocene atmospheric $\mathrm{pCO}_{2}$, Geology, submitted, 1991.

9. S. Savin, Ann. Rev. Earth Planet. Sci. 5, 319-355 (1977).

10. R. A. Berner, A. C. Lasaga and R. M. Garrels, Amer. J. Sci. 283, 641-683 (1983).

11. E. J. Barron and W. M. Washington, in The Carbon Cycle and Atmospheric CO2: Natural Variations Archean to Present, ed. by E. T. Sundquist and W. S. Broecker (Amer. Geophys. Union, Washington D.C., 1985), pp. 546-553.

12. T. Owen, R. D. Cess, and V. Ramanathan, Nature 277, 640-642 (1979).

13. J. F. Kasting, Palaeogeogr., Palaeoclimat., Palaeoecol. 75, 83-95 (1989).

14. W. S. Broecker and T.-H. Peng, Tracers in the Sea (Lamont-Doherty Geological Observatory, Palisades, New York, 1982), 690 pp.

15. R. A. Houghton and G. M. Woodwell, Scientific American 260, 36-44 (April, 1989).

16. R. B. Bacastrow and A. Bjorkstrom, in Carbon Cycle Modelling, SCOPE 16, ed. by B. Bolin (Wiley, New York, 1981), pp. 29-79.

17. H. D. Holland, The Chemistry of the Atmosphere and Oceans (Wiley, New York, 1978), $351 \mathrm{pp}$.

18.R. A. Berner, Geochim. Cosmochim. Acta 54, 2889-2890 (1990).

19. T. M. Gerlach, EOS 72, 249-255 (1991).

20. J. C. G. Walker, P. B. Hays and J. F. Kasting, J. Geophys. Res. 86, 9776-9782 (1981).

21. J. C. G. Walker, Origins of Life $16,117-127$ (1985).

22. J. F. Kasting and T. P. Ackerman, Science $\underline{234}$, 1383-1385 (1986). 
23. R. M. Rotty and C. D. Masters, in Atmospheric carbon dioxide and the global carbon cycle, ed. by J. R. Trabalka (U.S. Dept. of Energy, Washington, D.C., 1985), DOE/ER-0239.

24. J. C. G. Walker and J. F. Kasting, Effect of forest and fuel conservation on future levels of atmospheric carbon dioxide, Global and Planet. Change, in press.

25. H. W. Menard and S. M. Smith, J. Geophys. Res. 71, 4305-4325 (1966).

26. M. Meybeck, Amer. J. Sci. 287, 401-423 (1987).

27. I. G. Enting and G. I. Pearman, In The Changing Carbon Cycle: A Global Analysis, ed. by J. R. Trabalka and D. E. Reichle (Springer-Verlag, New York, 1986), pp. 425-458.

28. W. M. Post, T.-H. Peng, W. R. Emanuel, A. W. King, V. H. Dale and D. L. DeAngelis, Amer. Sci. 78, 310-326 (1990).

29. R. A. Houghton, J. E. Hobbie, J. M. Melillo, B. Moore, B. J. Peterson, Shaver G.R. and G. M. Woodwell, Ecol. Monogr. 53, 235-262 (1983).

30. R. P. Detwiler and C. A. S. Hall, Science 239, $42-47$ (1988).

31. P. P. Tans, I. Y. Fung and T. Takahashi, Science 247, 1431-1438 (1990).

32. G. Esser, Tellus 39B, 245-260 (1987).

33. J. C. G. Walker, Numerical Adventures in Earth History, Oxford University press, New York, in press.

34. J. Gribbin, Hothouse Earth (Grove Weidenfeld, New York, 1990), 273 pp. 